\title{
Model bias for South Atlantic Antarctic intermediate water in CMIP5
}

\author{
Chenyu Zhu ${ }^{1} @ \cdot$ Zhengyu Liu $^{1,2} \cdot \operatorname{Sifan} \mathrm{Gu}^{2}$
}

Received: 6 March 2017 / Accepted: 23 July 2017 / Published online: 29 July 2017

(C) The Author(s) 2017. This article is an open access publication

\begin{abstract}
Characterized by a salinity minimum in the mid-depth, the Antarctic Intermediate Water (AAIW) is an important component of global ocean water mass. The simulation of the AAIW in current climate models, however, has remained deficient, especially in the Atlantic sector. Here, we evaluate the simulation of the South Atlantic AAIW in eleven state-of-the-art coupled climate models. It is found that all the models show a common AAIW bias relative to the observation, with a saltier, warmer and lighter core located at a shallower depth. This AAIW bias seems to contribute to a deficient freshwater export by the Atlantic Meridional Overturning Circulation (AMOC), potentially overstabilizing the AMOC. The causes of the bias are investigated in sensitivity experiments using an ocean alone model. It is found that the AAIW bias is caused neither by the surface climate bias nor the North Atlantic bias, although is weakly affected by the inter-basin exchange. This left the conclusion that the AAIW bias is caused predominantly by the deficient model representation of ocean dynamics and mixing processes in the AAIW region.
\end{abstract}

Chenyu Zhu

zhuouc@163.com

1 Laboratory for Climate and Ocean-Atmosphere Studies(LaCOAS), School of Physics, Peking University, Beijing 100871, People's Republic of China

2 Department of Atmospheric and Oceanic Sciences and Nelson Center for Climatic Research, University of Wisconsin-Madison, 1225 W. Dayton St., Madison, WI 53706, USA
Keywords Antarctic intermediate water - Model bias . Surface climate $\cdot$ Inter-basin exchange $\cdot$ North Atlantic . Atlantic meridional overturning circulation freshwater transport

\section{Introduction}

The Antarctic Intermediate Water (AAIW) is a prominent water mass in the mid-depth. AAIW has generally been characterized as a salinity minimum water mass with a typical salinity of $34.2-34.4$ psu, with the core falling in the density range of $1027.2-1027.3 \mathrm{~kg} \mathrm{~m}^{-3}$ (e.g. Piola and Georgi 1982; Talley 1996). The AAIW originates from all the Southern Hemisphere subpolar oceans, ventilates into the Southern Hemisphere subtropical oceans, and then crosses the equator in the Atlantic and Pacific. Moreover, AAIW is an important component of the global heat, freshwater, carbon budgets and the global overturning circulation.

AAIW is formed near the subantarctic front (SAF). The formation process of AAIW is still poorly understood, although several mechanisms have been proposed. These processes include ice-sea and air-sea exchange of freshwater and heat (Santoso and England 2004), Ekman transport over the layer outcrop (Ribbe 2001; Rintoul and England 2002), interior mixing across the SAF (Molinelli 1981; Sloyan et al. 2010) and the deep winter convection in the southeastern Pacific Ocean mixed layer (McCartney 1977). The AAIW in the Atlantic is formed originally in the southwestern basin where the AAIW/ Subantarctic Mode Water (SAMW) from the southeast Pacific through Drake Passage joins the southward Brazil Current (McCartney 1977). The AAIW follows an anticyclonic basin-wide recirculation mainly driven by the wind stress in the subtropical South 
Atlantic (Schmid et al. 2000), and entrains into the subtropical lower thermocline.

In addition to its general importance in global heat, carbon and nutrients, recent studies suggest that the Atlantic AAIW might contribute to the stability of the Atlantic meridional overturning circulation (AMOC) through its impact on the AMOC freshwater transport at the southern boundary of the South Atlantic (e.g. Rahmstorf 1996; de Vries and Weber 2005; Drijfhout et al. 2011; Liu et al. 2014). This has motivated us here to examine the simulations of the AAIW in state-of-the-art climate models in the Atlantic.

There has been no systematic study on the AAIW in the Atlantic in climate models. Sloyan and Kamenkovich (2007) evaluated the simulations of SAMW and AAIW in IPCC AR4 models, and found that models generally provide a reasonable simulation of SAMW and AAIW but with a thinner and lighter layer and a limited equatorward extension. However, their study focused on the AAIW in Pacific and Indian Ocean sector. Sallée et al. (2013) studied the AAIW in the Coupled Modeling Intercomparison Project Phase 5 (CMIP5) models and suggested a warm and slightly salty bias. But, this study examined the Southern Ocean AAIW as a whole, without considering its zonal variation. Harrison et al. (2014) studied the AAIW in the Atlantic along with the sensitivity of the Atlantic circulation to bias in the freshwater input. They also identified a salty and warm bias in the AAIW, but this study was limited to only two models.

Here, we evaluate the simulation of AAIW in the CMIP5 models with the focus on the AAIW properties and their bias in the Atlantic Ocean. It is found that climate models show a generally warm and salty bias in the AAIW. This bias is contributed neither by the surface climate bias nor the North Atlantic bias, although is weakly affected by the inter-basin exchange. Instead, it is likely caused by the deficient representation of ocean dynamics in the AAIW region. Section 2 provides the information regarding the model and experimental design. In Sect. 3, we first compare the model with the observation to identify the model bias. We then study the potential causes of the AAIW bias in Sect. 4 by analyzing the CMIP5 models as well as sensitivity experiments in one or more ocean-alone models. Next in Sect. 5 we discuss the role of AAIW bias on the freshwater transport along $34^{\circ} \mathrm{S}$ in Atlantic. Finally, Sect. 6 presents the conclusion.

\section{Model and experiments}

\subsection{Model and observational data}

The simulations of AAIW are investigated in 11 CMIP5 models (Table 1; details of IPCC climate models can be found online at http://www.ipcc-data.org/sim/gcm monthly/AR5/Reference-Archive.html). All of the experiments used here are historical runs which were integrated with time-varying radiative gas concentrations and solar forcing period from 1861 to 2005. Following the recommendation of the IPCC, we define the multi-model mean climate as the 25-year average (1981-2005) of the simulated climate of the twentieth century. For the convenience of observation-model comparison, the annual and late winter (September-October for austral late winter, following Santoso and England 2004) climatology in climate models are interpolated to the observation grid points. Potential density is calculated from the monthly model temperature and salinity. Multi-model mean is the equal weighted average of all the used CMIP5 models.
Table 1 Details of the CMIP5 models used in this study

\begin{tabular}{llllr}
\hline Climate model & Institution (country) & Horizontal resolution Lat $\times$ Lon & $\begin{array}{l}\text { Vertical } \\
\text { resolu- } \\
\text { tion }\end{array}$ & Movs (Sv) \\
\hline BCC-CSM1.1 & BCC (China) & $1 / 3^{\circ}-1^{\circ} \times 1^{\circ}$ & 40 & 0.10 \\
CanESM2 & CCCma (Canada) & $0.9375^{\circ} \times 1.40625^{\circ}$ & 40 & 0.16 \\
CESM1-CAM5 & NCAR (USA) & $0.27^{\circ}-0.53^{\circ} \times 1.125^{\circ}$ & 60 & 0.00 \\
CMCC-CESM & CMCC (Italy) & $0.5^{\circ}-2^{\circ} \times 2^{\circ}$ & 31 & -0.22 \\
CNRM-CM5 & CNRM-CERFACS (France) & $1 / 3^{\circ}-1^{\circ} \times 1^{\circ}$ & 42 & 0.04 \\
GFDL-ESM2G & NOAA-GFDL (USA) & $1 / 3^{\circ}-1^{\circ} \times 1^{\circ}$ & 50 & 0.15 \\
GISS-E2-R & NASA-GISS (USA) & $1^{\circ} \times 1.25^{\circ}$ & 32 & 0.03 \\
HadGEM2-ES & MOHC (UK) & $1 / 3^{\circ}-1^{\circ} \times 1^{\circ}$ & 40 & 0.16 \\
IPSL-CM5A-LR & IPSL (France) & $0.5^{\circ}-2^{\circ} \times 2^{\circ}$ & 31 & -0.14 \\
MIROC-ESM & MIROC (Japan) & $0.94^{\circ} \times 1.4^{\circ}$ & 44 & -0.01 \\
MPI-ESM-P & MPI-M (Germany) & $1.5^{\circ} \times 1.5^{\circ}$ & 40 & -0.05 \\
\hline
\end{tabular}

Also shown is the overturning freshwater flux at $34^{\circ} \mathrm{S}$ in Atlantic (Movs) in each model 
The observational datasets used here are: ocean salinity and temperature from the World Ocean Atlas 2013 (WOA13, Zweng et al. 2013; Locarnini et al. 2013); precipitation from CPC merged analysis of precipitation (CMAP); evaporation from objectively analyzed air-sea fluxes (OAFlux) Project; Also used are UMD Simple Ocean Data Assimilation Reanalysis datasets (SODA version 2.2.4, Carton and Giese 2008), including ocean salinity, temperature and flow fields.

Also, an ocean-alone model Parallel Ocean Program version2 (POP2) is used later for sensitivity experiments. POP2 is a level coordinate model based on the parallel ocean program (POP) of the Los Alamos National Laboratory (Smith et al. 2010) and is the ocean component of the Community Climate System Model version 4 (CCSM4) and Community Earth System Model (CESM). In this study, the horizontal grid of POP2 has a uniform $3.6^{\circ}$ spacing in the zonal direction and non-uniform spacing in the meridional direction: it is $0.6^{\circ}$ near the equator, gradually increasing to the maximum $3.4^{\circ}$ at $35^{\circ} \mathrm{N} / \mathrm{S}$ and then decreasing poleward. It has 60 vertical levels and the resolution is uniform at $10 \mathrm{~m}$ in the upper $160 \mathrm{~m}$ and then increases to $250 \mathrm{~m}$ by a depth of about $3500 \mathrm{~m}$, below which it remains constant. A full description of the model physics can be found in Smith et al. (2010) and Danabasoglu et al. (2012).

\subsection{CORE-II and partial blocking (PB) experiments}

In this paper, we analyze ocean-ice alone experiments forced by the observed atmospheric and surface climate forcing in the coordinated ocean-ice reference experiments (CORE) framework, phase II (CORE-II) (Griffies et al. 2009; Danabasoglu et al. 2014) to detect the role of atmospheric deficiency on subsurface and intermediate water bias. The CORE-II experiments are global ocean-sea-ice coupled simulations using the common inter-annually varying atmospheric forcing (IAF) over the 60-year period from 1948 to 2007 described in Large and Yeager (2009).

Moreover, we designed a series of partial blocking (PB) experiments (Liu et al. 2002) under IAF forcing using POP2. In our PB experiments, ocean salinity and temperature in specific regions were restored (with a restoring time of 90 days) towards their respective monthly climatology in the observation. The PB experiments are used to investigate the role of specific regional bias on AAIW bias. We only focus on the results from the fifth forcing cycle of the simulations following Danabasoglu et al. (2014). More PB details are presented in Sect. 4.

\section{AAIW bias in the Atlantic in CMIP5}

In this section we compare the model against the observation for the water properties of annual and late winter in the Atlantic, with the focus on the AAIW temperature and salinity in 11 CMIP5 models.

The AAIW shows a general salty bias along the southern boundary $\left(\sim 34^{\circ}\right)$ of Atlantic across the CMIP5 models (Fig. 1) which is consistent with Liu et al. (2017). This salty bias is also similar to the results of IPCC AR4 models (Liu et al. 2014, figure 3a), suggesting that it has been a persistent bias in the state-of-the-art climate models. All the climate models, except for IPSL-CM5A-LR and CMCC-CESM, exhibit a fresh bias in the surface. This has been pointed out by Liu et al. (2014) in IPCC AR4 models and has been attributed, partly, to the tropical bias of double ITCZ: the model ITCZ is too far south in boreal winter such that it dilutes the subtropical salty surface water. In contrast to the surface, however, below the intermediate depth of $\sim 800 \mathrm{~m}$, all the models exhibit a salty bias. The spatial pattern of the bias in AAIW can also be seen in Figs. 2 and 3, which shows the total and bias of salinity in individual model. The bias patterns are similar no matter in the view of annual mean or late winter mean and it is more reasonable to plot the bias of late winter since AAIW is primarily formed within winter mixed layer. The salty bias is seen to exist in a larger area across Atlantic in many models, extending from $50^{\circ} \mathrm{S}$ to $30^{\circ} \mathrm{N}$. Furthermore, the total salinity in Fig. 2 shows that all CMIP5 models exhibited a limited

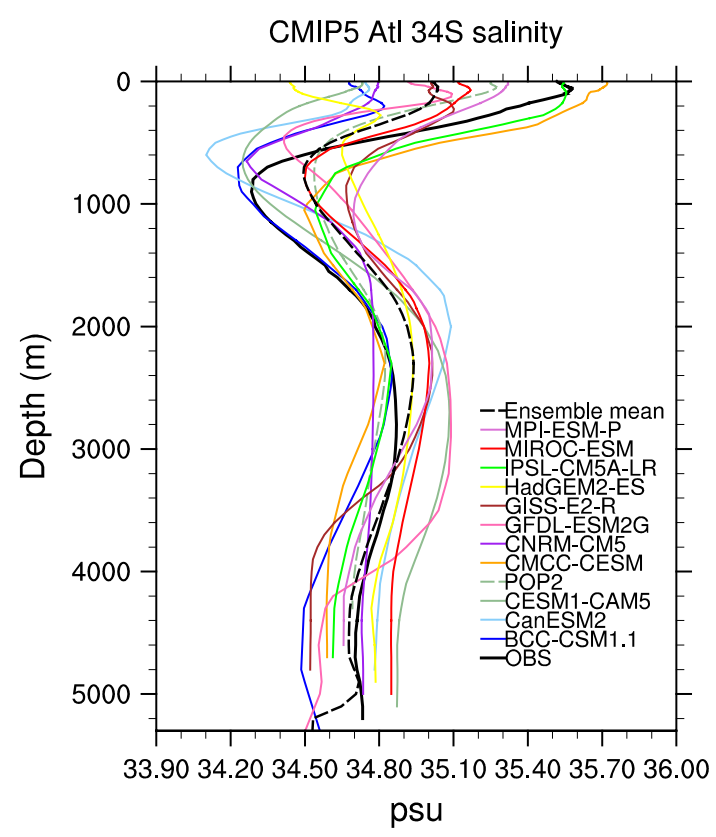

Fig. 1 Vertical profiles of zonal mean salinity (psu) along $34^{\circ} \mathrm{S}$ across the Atlantic in the CMIP5 models 

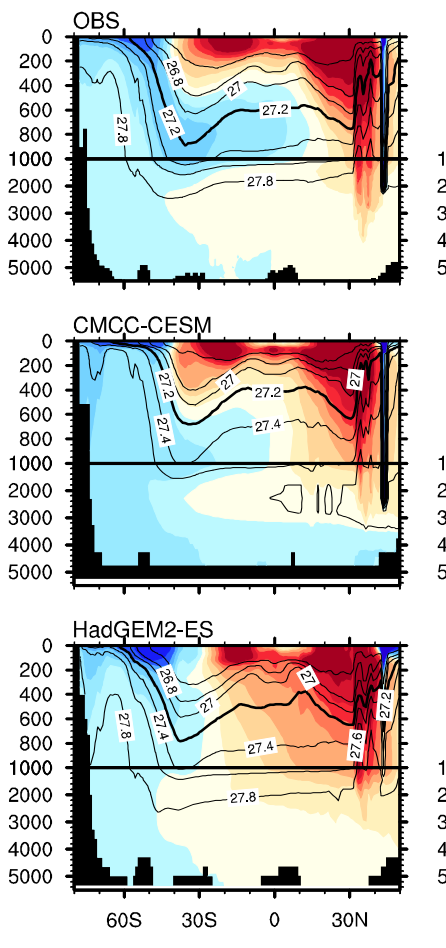
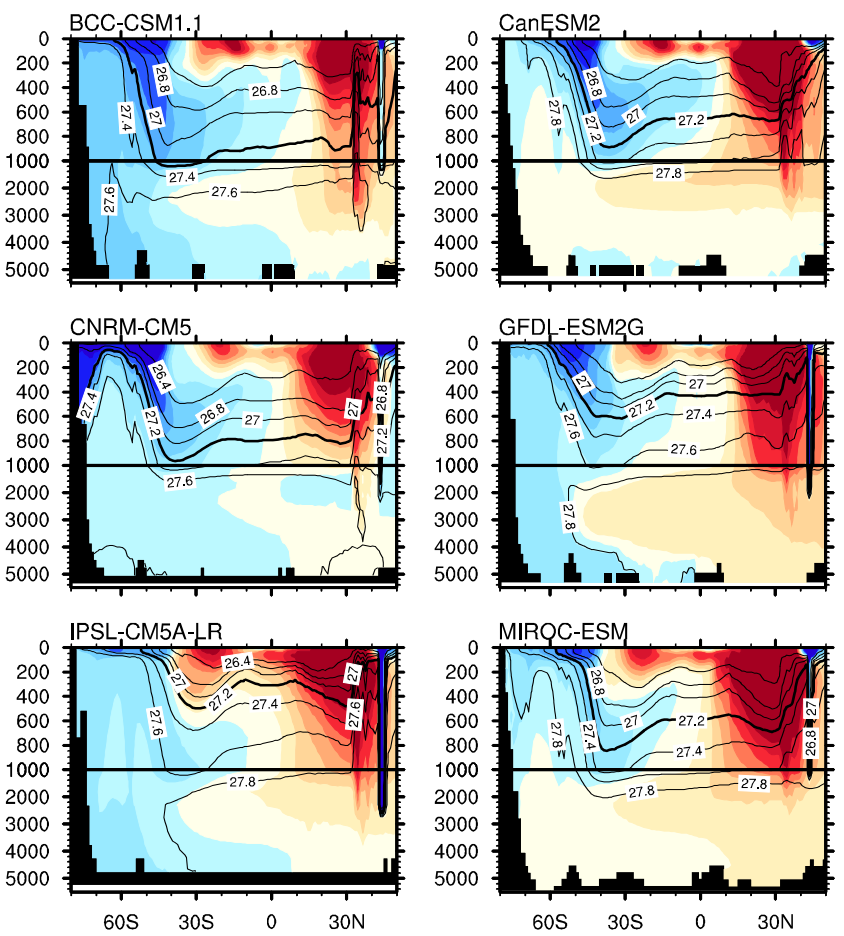
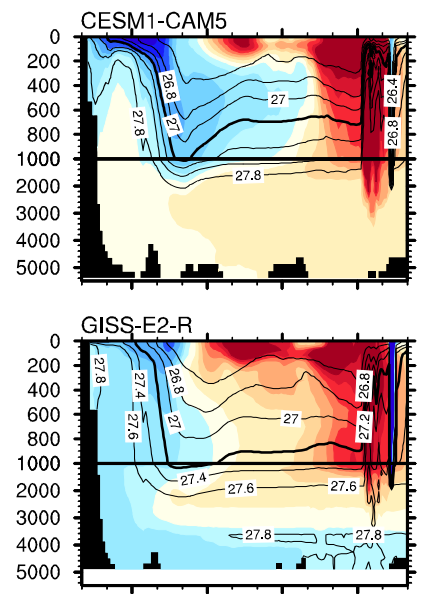

$\begin{array}{lllllllllllllll}33.6 & 33.8 & 34 & 34.2 & 34.4 & 34.6 & 34.8 & 35 & 35.2 & 35.4 & 35.6 & 35.8 & 36 & 36.2\end{array}$

Fig. 2 Annual zonal mean distribution of salinity (shading) and potential density (contour) in the Atlantic in WOA13 and CMIP5 models

AAIW equatorward extension relative to the observation. This feature is also similar in the Pacific (not shown). The reduced equatorward penetration of AAIW has been suggested to be caused by the too diffusive nature of the models (Sloyan and Kamenkovich 2007). Also, the simulated AAIW cores are mostly located at a shallower depth with a greater salinity than the observation, especially north of $30^{\circ} \mathrm{S}$. Since AAIW is an important component of AMOC, this common salty bias may also contribute to the biased freshwater transport, and in turn stability of the AMOC in these models.

The AAIW bias can also be seen more clearly in the T-S diagram. As a dominant water mass across south hemisphere, the AAIW has its unique watermass properties. Figure 4 shows the T-S diagram among different models and observation of South Atlantic. For the observation, AAIW is characterized by the salinity minimum water with a typical salinity of 34.2-34.4 psu with the core falling in the density range of $1027.2-1027.3 \mathrm{~kg} \mathrm{~m}^{-3}$ (e.g. Piola and Georgi 1982; Talley 1996). This salinity minimum feature is distinctive from its upper and lower water. In contrast, in the models, the salinity minimum is not as sharp as in the observation. The vague AAIW core is consistent with the small vertical gradient in Fig. 1. Moreover, model AAIWs have a common bias that is characterized by a saltier and warmer AAIW. It is tempting to speculate that the salty bias is compensated by the warm bias. This is, however, not always the case, because most models are on the lighter isopycnals, suggesting a dominance of the warm bias over the salty bias. This warm and salty bias increases northward in many models (Fig. 3). In contrast, these models do not show a significant common AAIW bias in the Pacific sector with little bias in the ensemble mean (not shown), implying the zonal variation of model AAIW bias. The question here is: what caused the bias in the South Atlantic AAIW?

\section{Potential causes of the model AAIW bias}

We further analyze the models to explore the potential causes of the AAIW bias. In particular, we focus on the potential roles of the surface climate bias, the subsurface biases through the inter-basin exchange and from the North Atlantic.

\subsection{The role of surface climate bias}

We first examine if the AAIW bias is caused by the bias in the surface climate in the coupled models. AAIW density surface outcrops near Antarctic polar front zone (APFZ). Sverdrup et al. (1942) firstly proposed that 

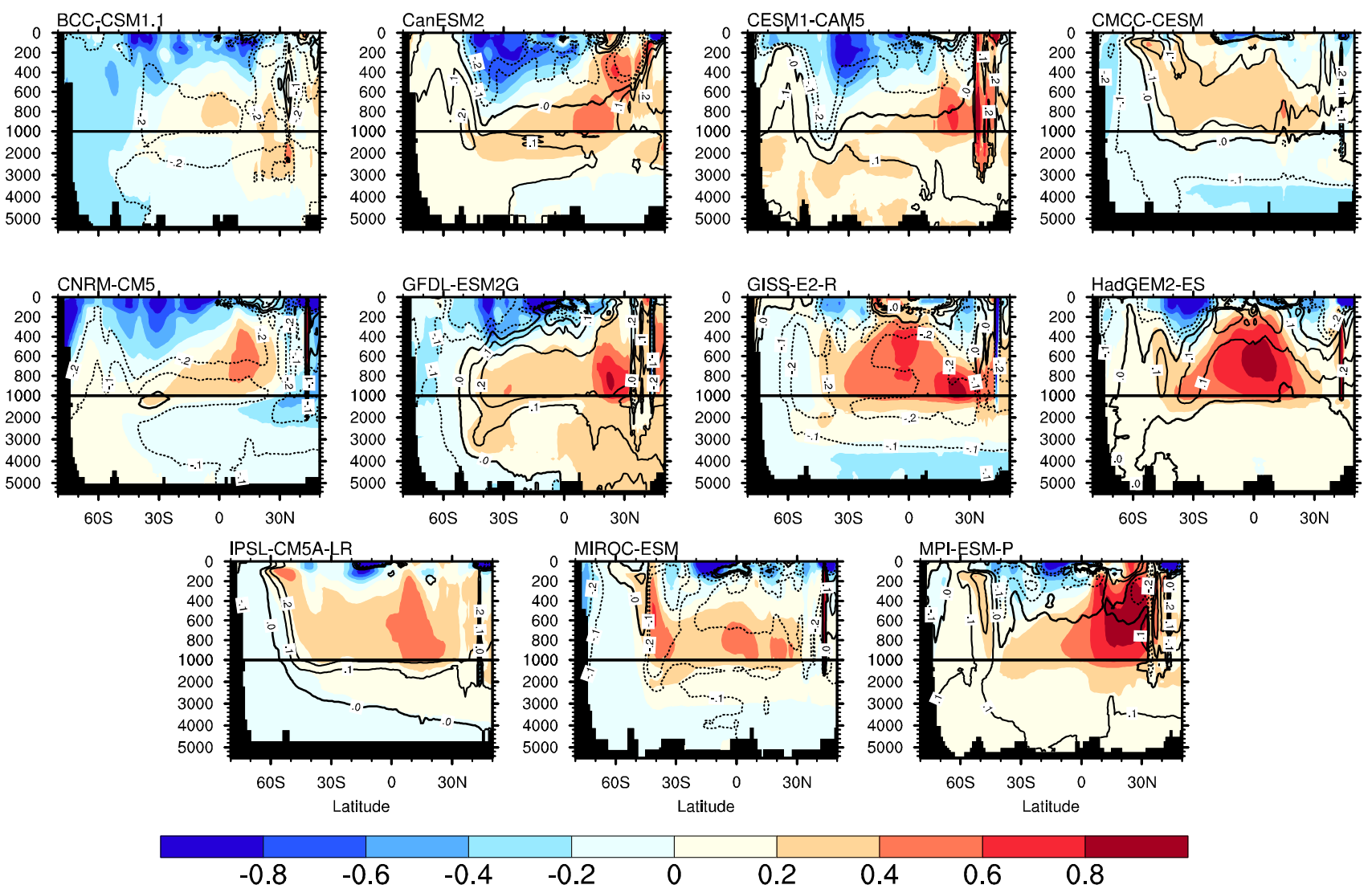

Fig. 3 Late winter zonal mean bias distribution of salinity (shading) and potential density (contour) in CMIP5 models

AAIW is formed by circumpolar subduction or alongisopycnal transport along the APFZ, supported by the circumpolar presence of AAIW. If this is true in model, AAIW bias may be tracked back to the surface climate bias far south. However, the model net precipitation shows a wet bias near the APFZ, as seen in the ensemble mean in Fig. 5, which causes a fresh APFZ in most models (Fig. 3). For many models, the fresh bias dominates almost the entire South Atlantic and the maximum fresh bias is located in the tropical South Atlantic, because of the southward shift in the Atlantic ITCZ in the model, which is a part of the tropical bias in climate models (Liu et al. 2014; Harrison et al. 2014). The fresh bias in the mid- and high latitude, is distinguished from the tropical bias, reflecting the excessive rainfall in the Southern Ocean storm track. The freshening surface water between $30^{\circ} \mathrm{S}$ and $40^{\circ} \mathrm{S}$ (Fig. 5d) in South Atlantic will subduct as the South Atlantic Subtropical Mode Water (SASTMW) and ventilate the thermocline water northward, leading a fresh thermocline bias at $34^{\circ} \mathrm{S}$ (Liu et al. 2015). Important here is that this fresh surface and thermocline bias in the upper $500 \mathrm{~m}$ across the South Atlantic and Southern Ocean is in contrast to the overall salty bias at the intermediate depth in the South Atlantic. Therefore, the
AAIW bias cannot be caused by the Southern Ocean surface climate bias.

To further detect the role of the common atmospheric deficiency and the resultant surface climate bias on setting the subsurface and intermediate water bias, we analyze the results from CORE-II experiments (Griffies et al. 2009; Danabasoglu et al. 2014). In CORE-II, the atmospheric deficiency and therefore the ocean surface climate bias is absent. However, the vertical salinity (temperature) distribution of Atlantic in CORE-II (Fig. 6) shows that the intermediate salty (warm) bias still exists although the surface bias is diminished. This further confirms that the AAIW bias is not caused mainly by the biases in surface salinity and temperature. This point is also consistent with the IPCC AR4 results (Liu et al. 2014) which shows the same fresh bias in the AAIW regardless of the surface flux adjustment in the model.

Moreover, the AAIW bias cannot even be related to the ocean upper $300 \mathrm{~m}$. We compare a series of PB experiments with no PB experiment (control, CIAF) under IAF forcing using POP2. The CIAF shows a consistent salinity and temperature bias pattern (Fig. 8b) similar to CORE-II results (Fig. 6) and its vertical salinity profile along $34^{\circ} \mathrm{S}$ resembles the CMIP5 multi-model mean in intermediate 
(a) $0-50 \mathrm{~S}$

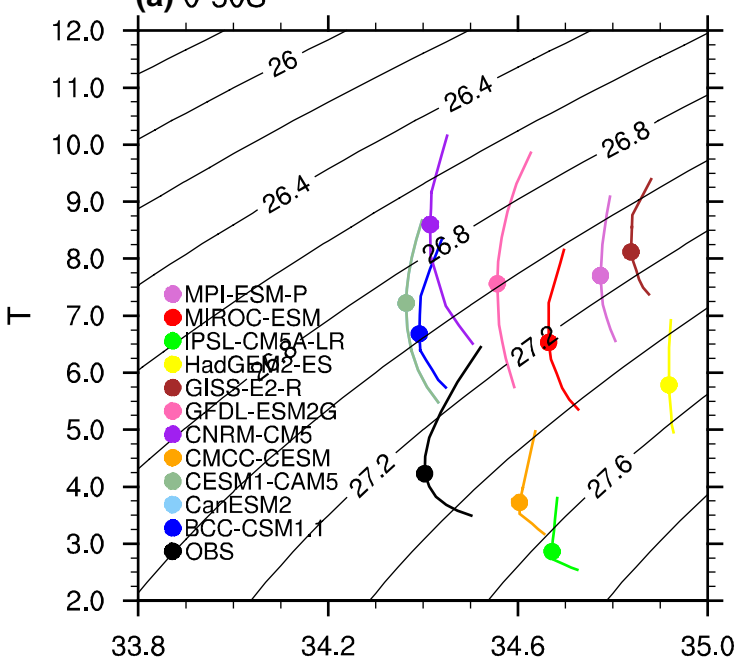

(c) $30-40 \mathrm{~S}$

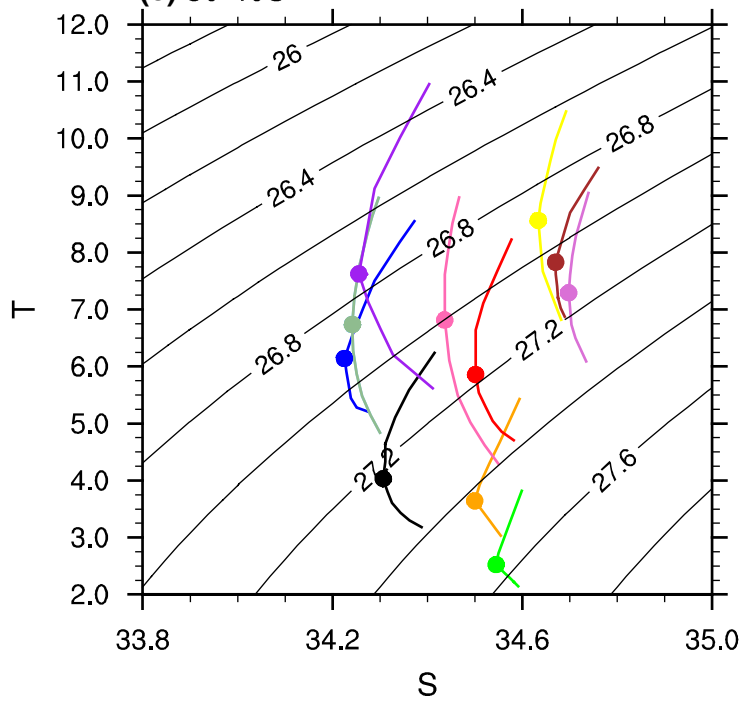

(b) $20-30 \mathrm{~S}$

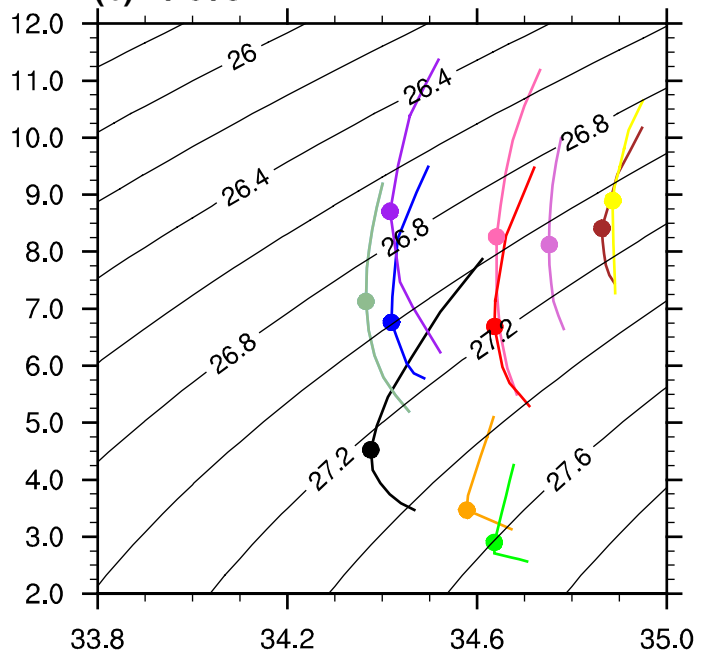

(d) $40-50 \mathrm{~S}$

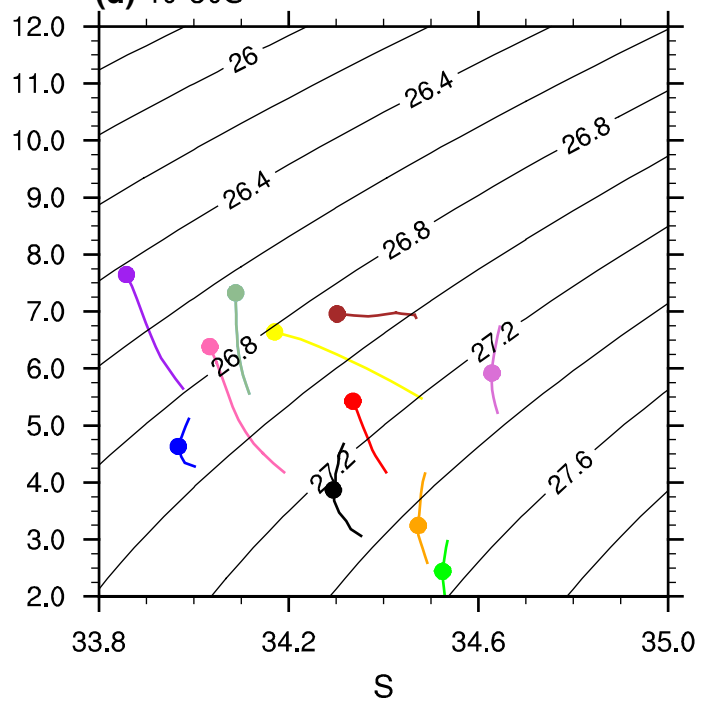

Fig. 4 AAIW T-S diagram in observation and CMIP5 models in different latitudes across the South Atlantic

depth (Fig. 1, POP2). In our PB experiments, global ocean salinity and temperature from surface to 100,200 and $300 \mathrm{~m}$ were restored (with a restoring time of 90 days) towards their respective monthly climatology in the observation, but with no substantial improvement in intermediate bias (not shown), which implies it is not the surface and mixed layer (one less than $300 \mathrm{~m}$ ) oceanic process that causes AAIW bias.

\subsection{The role of inter-basin exchange}

The bias in the Atlantic AAIW can be affected locally within the Atlantic sector, it can also be caused remotely by inter-basin exchanges with the upstream Pacific in the Drake Passage (McCartney 1977; Talley 1996) and the downstream Indian Ocean through the leakage of the
Agulhas Current (e.g. Rintoul 1991; Gordon et al. 1992; Weijer et al. 1999; Beal et al. 2011). McCartney (1977) suggested that AAIW is primarily a by-product of SAMW, formed in a deep convective mixed layer in the southeast Pacific Ocean off southern Chile, feeding into the Pacific Ocean via the Drake Passage to the southwest Atlantic. Therefore the bias in modeling the mixed layer in southeast Pacific could lead to the bias of South Atlantic AAIW. Here, we find that the mixed layer in the southeast Pacific in CMIP5 models is indeed much shallower than the observation (not shown). This is consistent with Danabasoglu et al. (2012) which indicated that the winter mixed layer around the ACC region seems to be shallower than the observation in both the coupled model CCSM4 and ocean alone model POP2. Gordon et al. (1992) also reported a significant interoceanic exchange of the intermediate water 
(a) OBS (E-P)

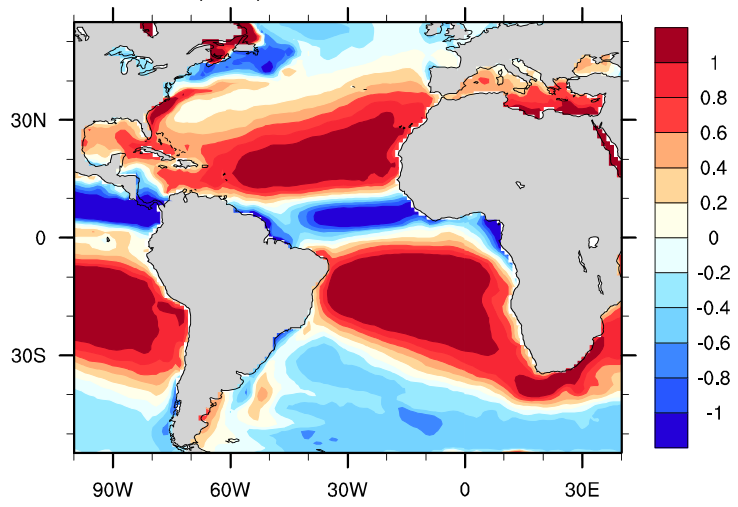

(c) OBS surface $(u, v) \& s$

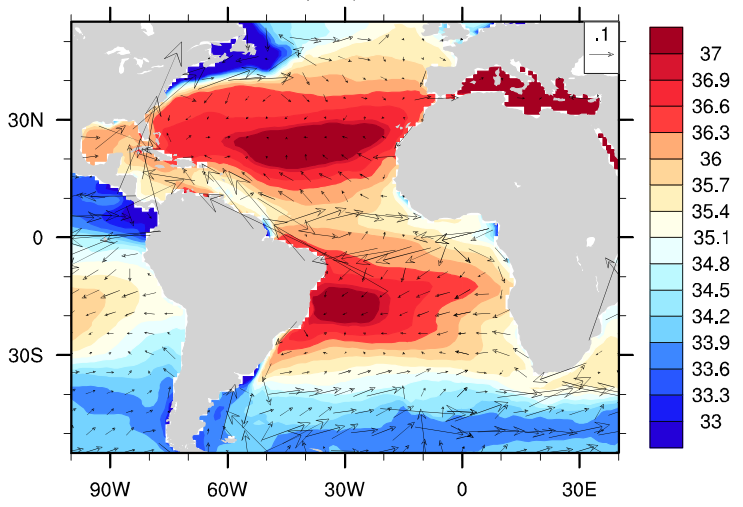

(b) Model mean (E-P) bias

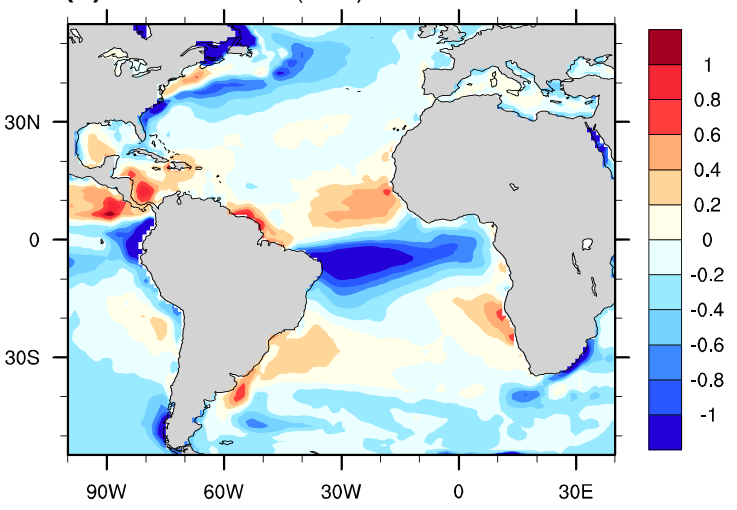

(d) Model mean surface $(u, v) \&$ s bias

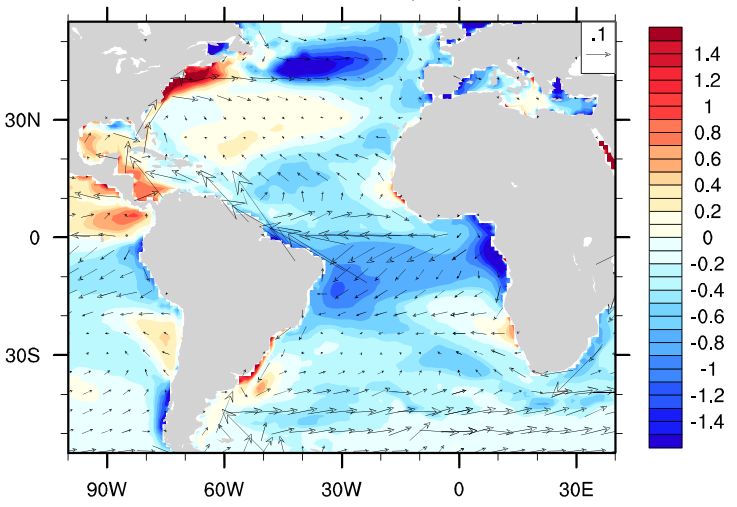

Fig. 5 Annual mean net precipitation (m/year) and surface salinity (psu) in observation (a, c) and their bias in multi-model mean (b, d). Two bottom panels $(\mathbf{c}, \mathbf{d})$ are overlaid by surface currents

between the South Atlantic and Indian oceans through the South Atlantic Current, Agulhas Retroflection and Benguela Current. Furthermore, several studies revealed that the overestimation of the inter-basin exchange could cause too salty South Atlantic and too fresh Indian Ocean due to the lack of spatial resolution to properly represent the inertial dynamics of the Agulhas retroflection and ring shedding process (Weijer and van Sebille 2014).

To investigate the role of inter-basin exchange, here in our sensitivity experiments, ocean temperature and salinity are restored in two regions from the surface to $5000 \mathrm{~m}$ depth: the downstream region of $20^{\circ}-50^{\circ} \mathrm{S}$ and $20^{\circ}-100^{\circ} \mathrm{E}$, and the upstream region of $40^{\circ}-70^{\circ} \mathrm{S}$ and $50^{\circ}-110^{\circ} \mathrm{W}$. The former includes part of Indian Ocean and Agulhas Current system while the latter includes the southeastern Pacific and Drake Passage. As such, the inter-basin areas are restored towards the observation completely. In the following we refer to the experiment as PB_SIOD.

The PB_SIOD result shows that the inter-basin exchange bias plays a minor role in the South Atlantic AAIW bias. There is a slight decrease in the salinity of intermediate water and a significant increase in the salinity of the thermocline water in South Atlantic (Fig. 8c). Both the salt intermediate bias around $40^{\circ} \mathrm{S}$ and fresh thermocline bias from $30^{\circ} \mathrm{S}-50^{\circ} \mathrm{S}$ of the South Atlantic in the upper $500 \mathrm{~m}$ (SA500m, short for this fresh bias region) in CIAF is corrected mainly by the southeastern Pacific Ocean through Drake Passage while the Indian ocean has no significant contribution, as demonstrated in further PB experiment for upstream region and downstream region, respectively (not shown). The bias in SA500m may contribute to the AMOC stability bias, a point to be returned later.

\subsection{The role of North Atlantic}

Since the salty bias in the AAIW appears to intensify all the way to the intermediate depth of the subtropical North Atlantic, one may also speculate that the bias may also be contributed by the North Atlantic formation of intermediate water. In observation, the AAIW salinity minimum terminates in the North Atlantic between $20^{\circ}-25^{\circ} \mathrm{N}$ (Fig. 7a), where it meets the Mediterranean Water in the eastern 

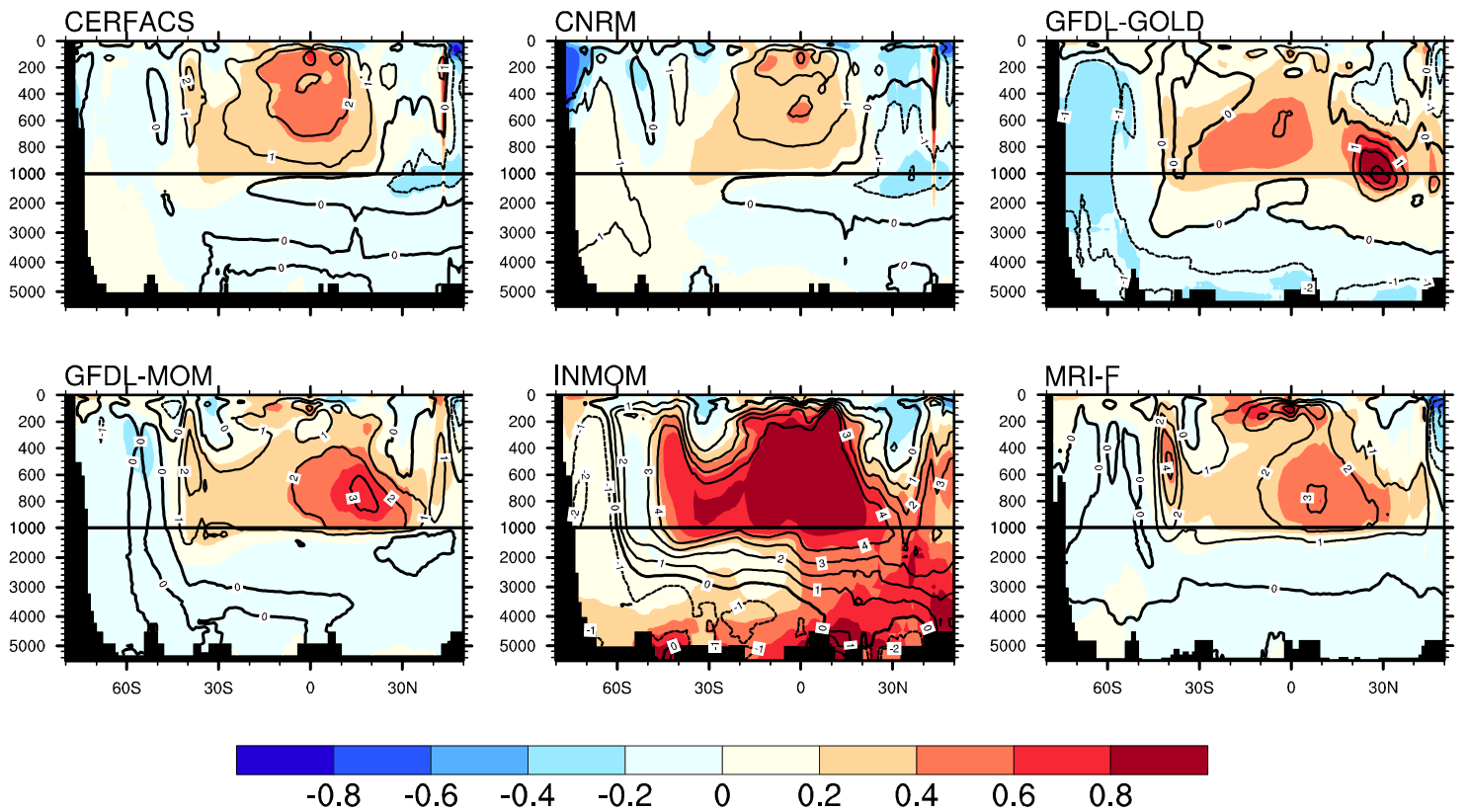

Fig. 6 Annual zonal mean bias distribution of salinity (shading) and potential temperature (contour) in the Atlantic in CORE-II models compared to WOA13

(a) OBS salt \& density

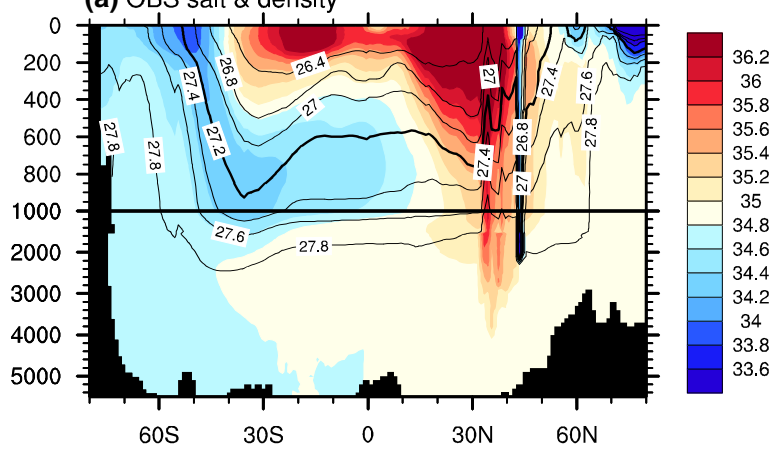

(c) Models mean salt bias \& density bias

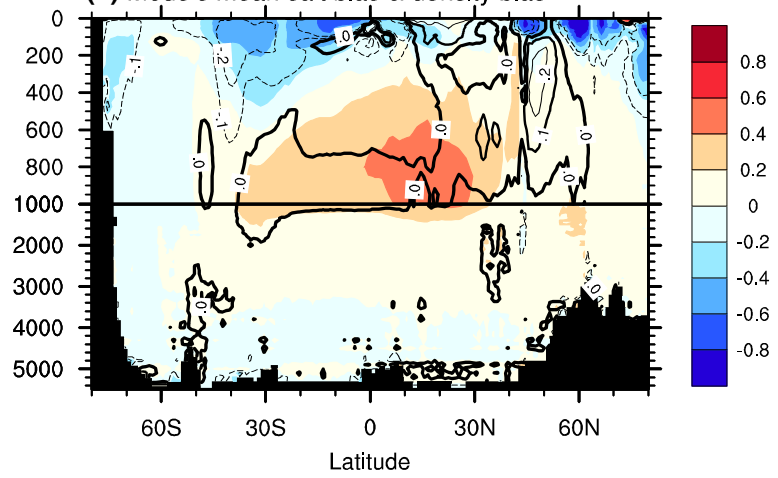

(b) Models mean salt \& density

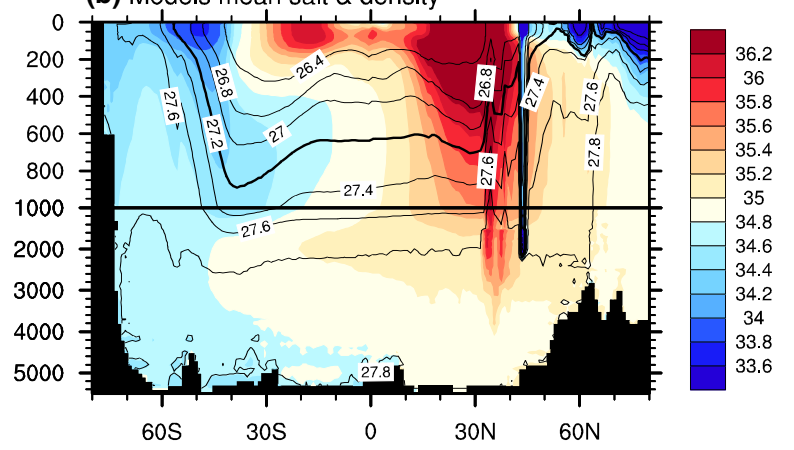

(d) Models mean temp bias \& MOC

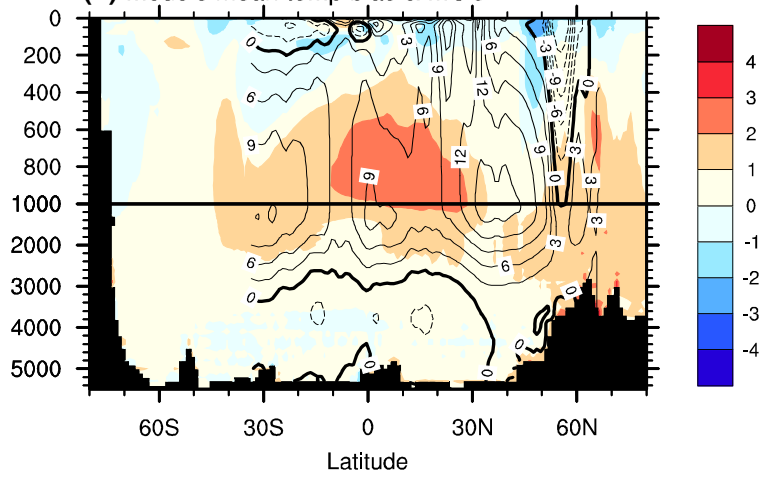

Fig. 7 Late winter zonal mean distribution of potential density and salinity in observation (a) and multi-model mean (b) and its mean bias (c) across the Atlantic. Also shown are the model MOC and the multi-model mean potential temperature bias (d) 


\section{(a) CIAF salt \& temp}

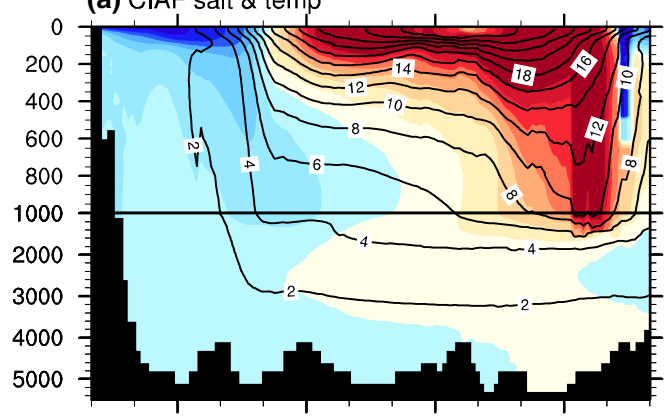

(c) PB SIOD-CIAF

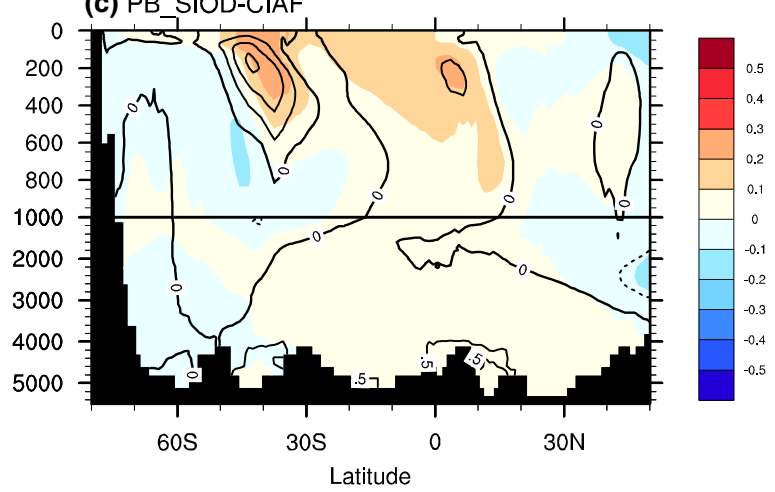

Fig. 8 Zonal mean distribution of salinity (shading) and potential temperature (contour) in CIAF (a) and its bias (b) across the Atlantic. The two bottom panels plot the salinity and potential temperature bias

Atlantic (Talley 1996). But in models, the confluence of these two watermasses locates more south, implying an enhanced Mediterranean Water penetration (Figs. 2, 7b). The multi-model mean bias across Atlantic in late winter shows that both intermediate salty and warm bias have their maxima located in the North Atlantic $\sim 15^{\circ} \mathrm{N}$ where the salty bias and warm bias compensate each other, leading to the near zero deviation in potential density (Fig. 7c, d). The bias calculation is also applied to each single model, in which the bias distribution is similar to the multi-model mean results (Fig. 3). With the depth getting deeper and deeper, the bias reaches further and further southward (not shown). It seems that the salty and warm bias originates from the eastern subtropical North Atlantic, especially near the Strait of Gibraltar and spread to the south. Moreover, the combination of fresh bias in the Mediterranean Sea with salty bias in the Atlantic could indicate too much exchange across Gibraltar Strait.

Consistent with the CMIP5 results, CIAF shows corresponding salty and warm bias maxima in northeastern Atlantic outside Gibraltar Strait. It should be mentioned here that there exists another bias maxima locating in tropical Atlantic upper $300 \mathrm{~m}$ which may due to the (b) CIAF-OBS

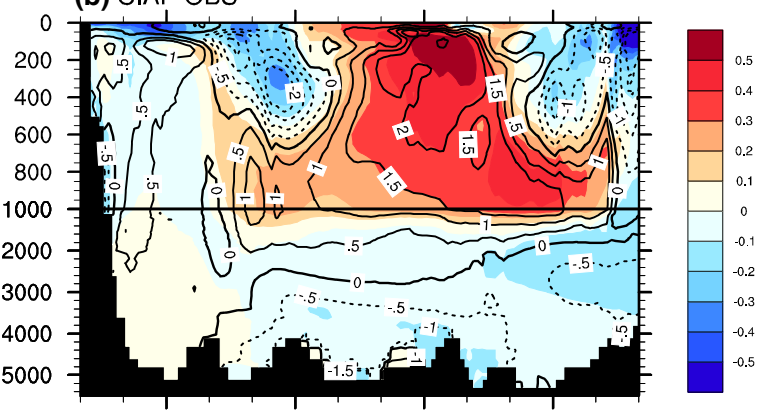

(d) PB Gib-CIAF

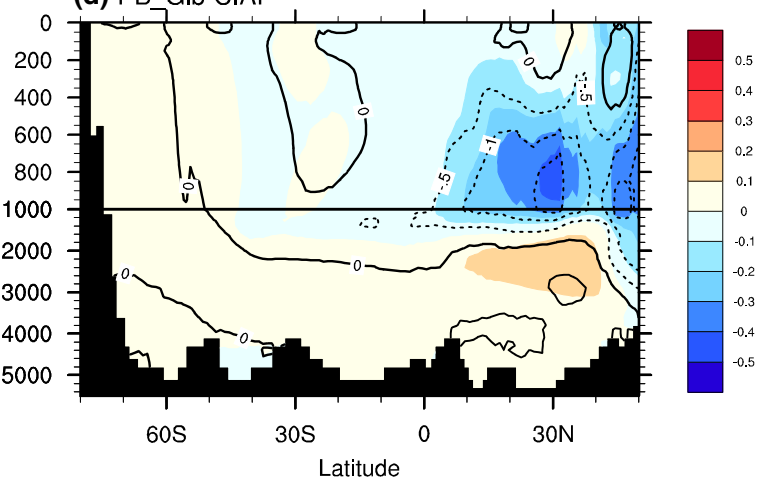

distribution compared with CIAF in two PB experiments: PB_SIOD (c) and PB_Gib (d)

surface forcing error, but it has little to do with intermediate water bias as demonstrated in surface PB experiments described in Sect. 4.1. To clarify the role of North Atlantic, we carry out another PB experiment similar to PB_SIOD except that the restoring region is located from $20^{\circ}$ to $40^{\circ} \mathrm{N}$ and from $30^{\circ}$ to $10^{\circ} \mathrm{W}$, namely PB_Gib hereafter, such that the water from the Mediterranean Sea is restored towards the observation. Surprisingly, there seems to be no relation between the North and South Atlantic salty bias in POP2. Figure 8d plots the difference between PB_Gib and CIAF. The freshening intermediate water in PB_Gib is confined locally in the subtropical North Atlantic, with no clearly south of equator. This muted effect of North Atlantic may be caused by the dominant northward flow in the AAIW across the equator in the subsurface North Brazil Current (not shown), which prevents the southward penetration of North Atlantic intermediate water. Therefore, the salty and warm bias maximum in the northeastern Atlantic outside Gibraltar Strait is more likely a regional phenomenon caused by excessive exchange between Mediterranean Sea and Atlantic resulting in the salty subtropical North Atlantic, with little impact on the bias in the South Atlantic AAIW. 


\section{The role of AAIW bias on the fresh water transport along $34^{\circ} \mathrm{S}$ in Atlantic}

Previous studies suggested that the overturning freshwater transport across $\sim 34^{\circ} \mathrm{S}$ (Movs) may serve as a diagnostic indicator of the AMOC stability that is associated with the salt-transport feedback (e.g. Rahmstorf 1996; de Vries and Weber 2005; Drijfhout et al. 2011; Liu et al. 2014). Present-day observations show an exporting of freshwater with the Movs in the range of -0.34 and $-0.1 \mathrm{~Sv}$, favoring a bistable AMOC. In many CGCMs, however, the AMOC freshwater transport is import, opposite to the observation. This may imply a monostable AMOC, and therefore an overstabilization bias in the models. Here we calculate Movs in these 11 CMIP5 models following Drijfhout et al. (2011) (Table 1), all models except CMCC-CESM and IPSL-CM5A-LR show a positive Movs (slightly negative values for MIROC-ESM and MPI-ESM-P), favoring a monostable AMOC. These two exceptions both have little salty bias in surface compared with the fresh surface bias in other models (Fig. 1). This highlights the role of surface climate bias in altering the AMOC stability as suggested by Liu et al. (2014).

Our POP2 experiments further show that weakened freshwater export Movs in the CIAF is contributed by the biases in the model ocean in both the upper and intermediate ocean in the Southern Ocean region. The contribution of the upper ocean inter-basin exchange can be seen in the enhanced freshwater export Movs from the control simulation CIAF $(-0.077 \mathrm{~Sv})$ to the PB experiment PB_SIOD $(-0.098 \mathrm{~Sv})$ in which the inter-basin exchanges are corrected towards the observation. The reduced AMOC freshwater export in CIAF seems to be caused partially by the fresh bias in the upper $500 \mathrm{~m}$ of the South Atlantic (defined as the region SA500m), because it can lead to a fresh return flow of AMOC, reducing the freshwater export. This is confirmed by an additional PB experiment in which ocean temperature and salinity are restored towards the observation in exactly the $\mathrm{SA500m}$ region (experiment $\mathrm{PB}_{-}$ SA500m, Fig. 9b), in which Movs export is increased to $-0.097 \mathrm{~Sv}$, almost the same as in PB_SIOD.

The further enhancement of the AMOC freshwater export from the intermediate depth of Southern Ocean is seen in another PB sensitivity experiment, in which the PB region is extended to $1200 \mathrm{~m}$ in the Southern Ocean $\mathrm{PB}_{-}$ $\mathrm{SO} 1200 \mathrm{~m}$ ) and the Movs is further enhanced to $-0.13 \mathrm{~Sv}$, falling into the range of the observations. Both $\mathrm{PB}_{-}$ SO1200m and PB_SA500m experiments show a correct of the fresh bias in the upper ocean (Fig. 9b, c), while PB_ $\mathrm{SO} 1200 \mathrm{~m}$ further shows a correction of the salty bias in the AAIW depth along ACC down to $1000 \mathrm{~m}$ at $30^{\circ} \mathrm{S}$ (Fig. 9c). The difference of Movs between PB_SO1200m and PB_ SA500m can be contributed to the role of AAIW in AMOC
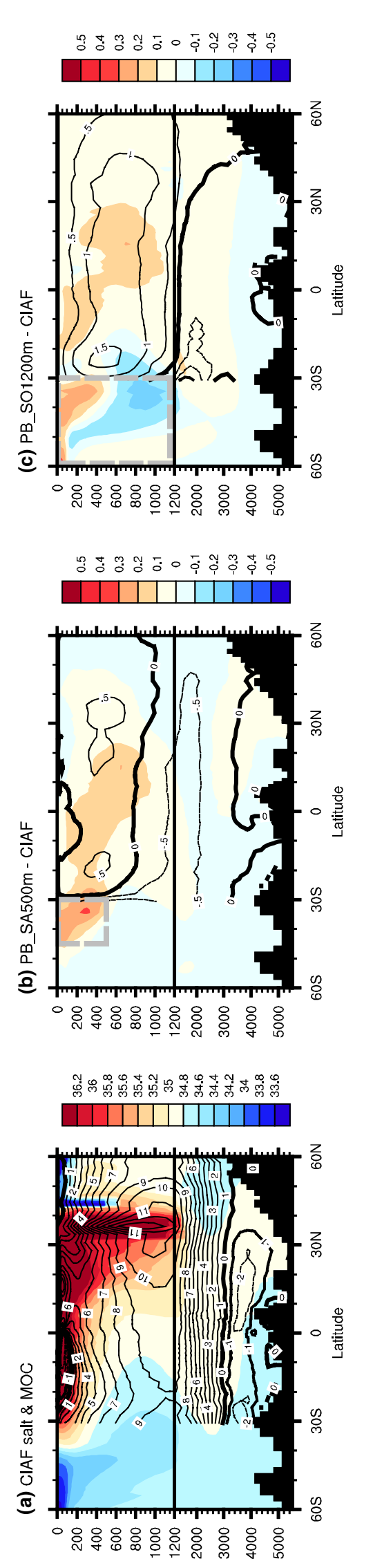
Table 2 Movs and freshwater transport (FWT, in Sv) in POP experiments

\begin{tabular}{lllll}
\hline & Movs & $\begin{array}{l}\text { Thermo- } \\
\text { cline water } \\
\text { FWT }\end{array}$ & $\begin{array}{l}\text { Intermedi- } \\
\text { ate water } \\
\text { FWT }\end{array}$ & $\begin{array}{l}\text { Deep water } \\
\text { FWT }\end{array}$ \\
\hline (1) CIAF(CTRL) & -0.077 & -0.103 & 0.006 & 0.020 \\
(2) PB_SA500m & -0.097 & -0.127 & 0.010 & 0.020 \\
(3) PB_ & -0.130 & -0.148 & -0.002 & 0.020 \\
SO1200m & & & & \\
& $\Delta$ Movs & $\iint \mathrm{v} \Delta \mathrm{Sdxdz}$ & $\iint \mathrm{S} \Delta \mathrm{vdxdz}$ & $\iint \Delta \mathrm{v} \Delta \mathrm{Sdxdz}$ \\
(3)-(2) & -0.033 & 0.027 & -0.047 & -0.012 \\
\hline
\end{tabular}

Also shown is the decomposition of Movs difference between two PB experiments

freshwater transport. To examine which depth of Southern Ocean water contributes most to the change of the total freshwater transport by AMOC, we firstly decompose the Movs change into three parts: $\iint \mathrm{v} \Delta \mathrm{Sdxdz}, \iint \mathrm{S} \Delta \mathrm{vdxdz}$ and $\iint \Delta \mathrm{v} \Delta \mathrm{Sdxdz}$. Our calculation (Table 2) shows that the second part that represents the $\Delta$ Movs induced by perturbation current on mean salinity is the biggest contributor. Actually in PB_SO1200m, the AMOC is about $1 \mathrm{~Sv}$ stronger than that in PB_SA500m or CIAF (Fig. 9c) in upper $800 \mathrm{~m}$, which will import more salty thermocline water into the Atlantic Basin, or, equivalently, export more freshwater out of the Atlantic Basin. This is further confirmed by the calculation of the freshwater transport (FWT) into three components in the depth ranges of the thermocline water $(0-600 \mathrm{~m})$, intermediate water $(600-1200 \mathrm{~m})$ and deep water (1200-4000 m), respectively (Table 2). Compared with those in deeper layers, surface and thermocline waters (and their bias) have a larger contribution to FWT (and its bias) across $34^{\circ} \mathrm{S}$. This larger contribution of surface and thermocline waters is consistent with results from Liu and Liu (2013) and Liu et al. (2014). Corresponding with the decomposition analysis, these results show that AAIW bias could contribute to the deficient AMOC freshwater export mainly by its impact of the bias on the strength of AMOC return flow. Therefore, we speculate that both upper ocean bias and AAIW bias could contribute to the overstabilization of AMOC in climate models.

\section{Conclusion}

This study examines the simulations of AAIW in current climate models and furthermore the possible mechanisms of the model bias in Atlantic AAIW. In general, the CMIP5 models show a salty and warm AAIW, especially north of $30^{\circ} \mathrm{S}$ with its core located on a lighter density surface. Both salinity and temperature biases increase northward and reach their maxima in the North Atlantic outside the
Gibraltar Strait where the AAIW meets the Mediterranean Water. The AAIW bias further induces a reduction of AMOC freshwater export from the South Atlantic, mainly by the impact of the AAIW bias on the strength of AMOC return flow. Therefore, in addition to the surface climate bias, especially in the tropics (Liu et al. 2014), ocean model bias in AAIW also appears to contribute to the reduced AMOC freshwater export, and in turn, potentially an overstabilization of AMOC in current climate models.

Three hypotheses are tested on the cause of the AAIW bias: (1) the surface climate bias near APFZ, (2) the interocean exchange and (3) the North Atlantic impact. These hypotheses are tested with CORE-II experiments and a series of PB experiments in POP2. It is found that the AAIW bias is caused neither by the surface bias nor the North Atlantic bias, although is weakly affected by the inter-basin exchange. This leaves the only possibility that the salty and warm AAIW is caused mainly by the poor representation of ocean interior dynamics and mixing processes locally in the AAIW region. This hypothesis needs to be tested by model simulations using different parameterization regarding these processes which will be our future studies due to the current computation limitation. Here, we recommend that much further work is needed to identify, and then correct, ocean model dynamic processes for this AAIW bias.

Acknowledgements We thank Dr. G. Danabasoglu and Dr. Stephen G. Yeager for discussion of CORE-II simulation and Dr. M. Winton for our better understanding of North Atlantic bias. We gratefully acknowledge the constructive comments from two anonymous reviewers. CMAP Precipitation data is provided by the NOAA/OAR/ESRL PSD, Boulder, Colorado, USA, from their Web site at http://www.esrl. noaa.gov/psd/. Evaporation data is provided by the WHOI OAFlux project (http://oaflux.whoi.edu) funded by the NOAA Climate Observations and Monitoring (COM) program. This work is supported by National Natural Science Foundation of China (NSFC41630527) and US National Science Foundation (NSF P2C2). All experiments are performed on the supercomputer at the LaCOAS, Peking University.

Open Access This article is distributed under the terms of the Creative Commons Attribution 4.0 International License (http:// creativecommons.org/licenses/by/4.0/), which permits unrestricted use, distribution, and reproduction in any medium, provided you give appropriate credit to the original author(s) and the source, provide a link to the Creative Commons license, and indicate if changes were made.

\section{References}

Beal LM, De Ruijter WP, Biastoch A, Zahn R (2011) On the role of the Agulhas system in ocean circulation and climate. Nature 472(7344):429-436

Carton JA, Giese BS (2008) A reanalysis of ocean climate using simple ocean data assimilation (SODA). Mon Weather Rev 136:2999-3017. doi:10.1175/2007MWR1978.1 
Danabasoglu G, Bates S, Briegleb BP, Jayne SR, Jochum M, Large WG, Peacock S, Yeager SG (2012) The CCSM4 ocean component. J Clim 25:1361-1389

Danabasoglu G et al (2014) North Atlantic simulations in coordinated ocean-ice reference experiments phase II (CORE-II). Part I: mean states. Ocean Modell 73(1):76-107

de Vries P, Weber SL (2005) The Atlantic freshwater budget as a diagnostic for the existence of a stable shut down of the meridional overturning circulation. Geophys Res Lett 32:L09606. doi:10.1029/2004GL021450

Drijfhout SS, Weber S, van der Swaluw E (2011) The stability of the MOC as diagnosed from model projections from pre-industrial, present and future climates. Clim Dyn 37(7-8):15751586. doi:10.1007/s00382-010-0930-z

Gordon AL, Weiss RF, Smethie WM Jr, Warner MJ (1992) Thermocline and intermediate water communication between the South Atlantic and Indian Oceans. J Geophys Res 97:7223-7240

Griffies SM et al (2009) Coordinated ocean-ice reference experiments (COREs). Ocean Modell 26:1-46

Harrison M, Adcroft A, Hallberg R (2014) Atlantic watermass and circulation response to persistent freshwater forcing in two coupled general circulation models. Clim Dyn 42:59-68. doi:10.1007/s00382-013-1798-5

Large WG, Yeager SG (2009) The global climatology of an interannually varying air-sea flux data set. Clim Dyn 33:341-364

Liu W, Liu Z (2013) A diagnostic indicator of the stability of the Atlantic meridional overturning circulation in CCSM3. J Clim 26:1926-1938

Liu Z, Wu L, Gallimore R, Jacob R (2002) Search for the origins of Pacific decadal climate variability. Geophys Res Lett 29(10):1404. doi:10.1029/2001GL013735

Liu W, Liu Z, Brady EC (2014) Why is the AMOC monostable in coupled general circulation models? J Clim 27(6):2427-2443

Liu W, Liu Z, Cheng J, Hu H (2015) On the stability of the Atlantic meridional overturning circulation during the last deglaciation. Clim Dyn 44:1257-1275

Liu W, Xie SP, Liu Z, Zhu J (2017) Overlooked possibility of a collapsed Atlantic Meridional Overturning Circulation in warming climate. Sci Adv 3:e1601666. doi:10.1126/sciadv.1601666

Locarnini RA, Mishonov AV, Antonov JI, Boyer TP, Garcia HE, Baranova OK, Zweng MM, Paver CR, Reagan JR, Johnson DR, Hamilton M, Seidov D (2013) World Ocean Atlas 2013, Volume 1: Temperature. In: Levitus S (ed) A. Mishonov Technical Ed.; NOAA Atlas NESDIS, vol 73

McCartney MS (1977) Subantarctic Mode Water. Deep-Sea Res 24:103-119

Molinelli ET (1981) The Antarctic influence on Antarctic intermediate water. J Mar Res 39:267-293

Piola AR, Georgi DT (1982) Circumpolar properties of Antarctic intermediate water and subantarctic mode water. Deep-Sea Res 29:687-711
Rahmstorf S (1996) On the freshwater forcing and transport of the Atlantic thermohaline circulation. Clim Dyn 12:799-811

Ribbe J (2001) Intermediate water mass production controlled by Southern Hemisphere winds. Geophys Res Lett 28(3):535-538

Rintoul S (1991) South Atlantic interbasin exchange. J Geophys Res 96(C2):2675-2692. doi:10.1029/90JC02422

Rintoul S, England M (2002) Ekman transport dominates local air-sea fluxes in driving variability of subantarctic mode water. J Phys Oceanogr 32(5):1308-1321

Sallée JB, Shuckburgh E, Bruneau N, Meijers AJS, Bracegirdle TJ, Wang Z, Roy T (2013) Assessment of Southern Ocean water mass circulation and characteristics in CMIP5 models: Historical bias and forcing response. J Geophys Res Oceans 118:1830 1844. doi:10.1002/jgrc.20135

Santoso A, England MH (2004) Antarctic Intermediate Water circulation and variability in a coupled climate model. J Phys Oceanogr $34: 2160-2179$

Schmid C, Siedler G, Zenk W (2000) Dynamics of intermediate water circulation in the subtropical South Atlantic. J Phys Oceanogr 30:3191-3211

Sloyan BM, Kamenkovich IV (2007) Simulation of subantarctic mode and antarctic intermediate waters in climate models. J Clim 20(20):5061-5080. doi:10.1175/JCLI4295.1

Sloyan BM, Talley LD, Chereskin TK, Fine R, Holte J (2010) Antarctic intermediate water and subantarctic mode water formation in the southeast pacific: the role of turbulent mixing. J Phys Oceanogr 40(7): 1558-1574

Smith RD et al (2010) The Parallel Ocean Program (POP) reference manual, ocean component of the Community Climate System Model (CCSM). Los Alamos National Laboratory Technical Report LAUR-10-01853, $141 \mathrm{pp}$. http://www.cesm.ucar.edu/ models/cesm1.0/pop2/doc/sci/POPRefManual.pdf. Accessed 12 July 2017

Sverdrup HU, Johnson MW, Fleming RH (1942) The oceans: their physics, chemistry, and general biology. Prentice Hall, pp 1087

Talley LD (1996) Antarctic Intermediate Water in the South Atlantic. In: Wefer $\mathrm{G}$ et al (eds) The South Atlantic: present and past circulation. Springer, Berlin, pp 219-238

Weijer W, Van Sebille E (2014) Impact of Agulhas leakage on the Atlantic overturning circulation in the CCSM4. J Clim 27(1):101-110

Weijer W et al (1999) Impact of interbasin exchange of the Atlantic overturning circulation. J Phys Oceanogr 29:2266-2284

Zweng MM, Reagan JR, Antonov JI, Locarnini RA, Mishonov AV, Boyer TP, Garcia HE, Baranova OK, Johnson DR, Seidov D, Biddle MM (2013) World Ocean Atlas 2013, Volume 2: Salinity. In: Levitus S (ed) A. Mishonov Technical Ed.; NOAA Atlas NESDIS 74 